\title{
Benign Intestinal Neoplasm
}

National Cancer Institute

\section{Source}

National Cancer Institute. Benign Intestinal Neoplasm. NCI Thesaurus. Code C4609.

A non-metastasizing neoplasm arising from the small or large intestine. 